\title{
Revisão bibliométrica no tema Empreendedorismo Imigrante e Étnico
}

\author{
Eduardo Picanço $\mathrm{Cruz}^{\mathrm{A}}$ e Roberto Pessoa de Queiroz Falcão ${ }^{\mathrm{AB1}}$ \\ ${ }^{A}$ Universidade Federal Fluminense, UFF/RJ, Niterói/RJ, Brasil \\ ${ }^{B}$ Pontifícia Universidade Católica do Rio de Janeiro, PUC/RJ, Rio de Janeiro/RJ, Brasil
}

\section{DETALHES DO ARTIGO}

\section{Histórico do artigo:}

Recebido em 28 de julho de 2016

Aceito em 07 de dezembro de 2016

Disponível online: 31 de dezembro de 2016

Sistema de Revisão "Double Blind Review"

Editor científico:

Ilan Avrichir

\section{Palavras-chaves:}

Imigração

Empreendedorismo imigrante

Empreendedorismo étnico

Enclave étnico

\begin{abstract}
RESUMO
O debate sobre a imigração de milhares de refugiados para Europa e sua assimilação pela sociedade e economia locais, apresenta-se como um tema em voga na atualidade. Adicionalmente, o empreendedorismo internacional de enclave étnico tem sido estudado como uma das formas de mobilidade social e integração destes grupos. Diversas comunidades de imigrantes de várias etnias têm sido objeto de estudo, no entanto, o brasileiro imigrante tem sido pouco estudado quanto a seu perfil, cultura e comportamento empreendedor. As pesquisas bibliométricas realizadas dentro do tema de empreendedorismo imigrante e étnico, apontam para uma mudança em seu enfoque original em 'economias de enclave', 'empresas étnicas' e 'enraizamento social' para investigações relacionadas aos 'empresários imigrantes', às 'redes de negócios imigrantes' e aos 'empresários transnacionais'. Este artigo pretende, portanto, apresentar o resultado de um estudo bibliométrico contemplando os trabalhos seminais, as principais teorias internacionais a respeito de empreendedorismo imigrante e de enclaves étnicos, assim como identificar lacunas da literatura brasileira e internacional, expandindo este campo de pesquisa. Como principais resultados, os autores apresentam uma análise de conceitos, teorias e artigos mais citados neste campo de pesquisa e apontam para possíveis caminhos futuros de investigação.
\end{abstract}

(C) 2016 Internext | ESPM. Todos os direitos reservados!

\section{Introdução}

O objetivo do presente estudo é o de contribuir com a expansão das pesquisas sobre empreendedorismo em seus aspectos internacionais, particularmente referente ao empreendedorismo realizado por imigrantes, apontando para novos caminhos de investigação.

O debate referente à imigração está cada vez mais relevante e presente na imprensa internacional, tanto devido ao grande movimento de refugiados sírios e africanos buscando asilo na Europa, quanto ao polêmico discurso do candidato à presidência americana Donald Trump enfatizando a questão mexicana nos EUA.

\footnotetext{
${ }^{1}$ Contato do autor: E-mail: robertopqfalcao@gmail.com
}

Porém, o que esses fatos têm trazido à tona, é uma ênfase negativa ao fenômeno migratório, já que a principal preocupação dos líderes mundiais é a de como acolher este grande contingente de pessoas que abandonaram sua história - incluindo bens materiais, diplomas e trabalho - para chegarem aos países receptores desprovidos de todas essas posses no afã de reconstruírem suas vidas.

Por outro lado, alguns estudos sobre imigração destacam um ângulo específico da questão, denotando o impacto positivo do empreendedorismo na geração de renda e mobilidade social. Exemplos descritos na literatura internacional como os refugiados cubanos em Miami, dominicanos em Nova York, chineses em suas chinatowns, entre outros, 
corroboram a importância e atualidade do tema. (e.g. Portes \& Zhou, 1992; Zhou, 2004).

Porém, a literatura nacional ainda carece de textos sobre empreendedorismo imigrante. Pesquisas acerca da situação dos empreendedores brasileiros no exterior quase inexistem, mesmo a taxa total de empreendedorismo no país (TTE) de nossa nação de ter sido de 39,3\%, acordo com a Global Entrepreneurship Monitorem 2015, o que aponta para 52 milhões de indivíduos entre 18 e 64 anos engajados em atividades empreendedoras (GEM, 2016).

O início do fenômeno migratório brasileiro para diversos países foi identificado a partir da década de 1980, em decorrência da severa crise econômica que assolou o país. Diversos estudos concordam com esse marco, variando apenas o destino final: Japão (Assis \& Sasaki, 2000), Estados Unidos (Margolis, 2003) e Portugal (Vitorio, 2007), por exemplo. A questão ficou tão evidente que, em 2005, o Governo brasileiro criou uma Comissão Parlamentar Mista de Inquérito para melhor apurar o fenômeno, o que denota a importância do tema.

A literatura internacional apresenta duas pesquisas bibliométricas recentes sobre o assunto, realizadas por Ma, Zhao, Wang e Li (2013) e AliagaIsla e Rialp (2013).

A primeira pesquisa aponta para os principais temas do campo do empreendedorismo imigrante discutidos até então. De acordo com os autores o debate encontra-se focado na figura dos 'empresários imigrantes', nas 'redes de negócios imigrantes' e nos 'empresários transnacionais'.

Já o segundo artigo apresenta evidências de que a maioria dos estudos sobre empreendedorismo imigrante se concentrou nas comunidades estabelecidas nos EUA, seguido pela Europa e Oceania, abrindo caminho para a justificativa de uma pesquisa nacional. Além disso, estes autores identificaram que os estudos tiveram um nível individual de análise e uma perspectiva dedutiva preponderante. Segundo sua análise, há uma escassez na construção das teorias e de estudos qualitativos neste campo, além de lacunas da literatura relativas ao empreendedorismo imigrante em países em desenvolvimento, da América Latina, Ásia, ou nos BRICs.

Os autores também apontam para existência de poucos estudos comparativos já que tanto os contextos onde se inserem quanto suas culturas dos empreendedores imigrantes influenciam seus resultados. Os autores destacam assim a necessidade de se realizarem mais estudos sobre as características de cada população imigrante, do empreendedorismo derivado delas e sua comparação.

A revisão da literatura nacional indica outras lacunas. Martes e Rodriguez (2004) evidenciam oportunidades de estudos relacionados tanto com as comunidades brasileiras no exterior quanto relativa aos significativos contingentes de imigrantes estrangeiros que aportam no Brasil.

O presente artigo tem enfoque nos trabalhos sobre empreendedorismo imigrante, empreendedorismo étnico, teorias dos capitais, e enclaves étnicos, presentes na literatura internacional e nacional. Dessa forma, o objetivo foi revisitar o tema, incluindo à base de dados 183 novos trabalhos internacionais, publicados após os estudos bibliométricos citados.

\section{Metodologia}

Foi realizado um estudo bibliométrico buscando-se a limitação do viés, para dar subsídios para sua replicabilidade em estudos futuros (Jones, Coviello, \& Tang, 2011), produzindo-se um resumo científico das evidências desta área do conhecimento (Petticrew, 2006).

A finalidade desta rigidez metodológica e detalhamento dos procedimentos, portanto, baseiase em alguns princípios destacados por Thorpe, Holt, Macpherson \& Pittaway (2005): transparência, clareza, foco, unificar pesquisas e pesquisadores de todo mundo no tema, igualdade, acessibilidade, ampla cobertura e gerar uma síntese.

Para proceder este estudo considerou-se, conforme Aliaga-Isla e Rialp (2013) os seguintes critérios: (i) definição internacional de empreendedorismo imigrante (Chaganti \& Greene, 2002; Sasse \& Thielemann, 2005); (ii) o âmbito do empreendedorismo (Acs, Audretsch, \& Evans 1994; Vinogradov \& Kolvereid 2007; Wennekers, Thurik, van Stel \& Noorderhaven 2003); (iii) Apenas os idiomas inglês e português, sendo o inglês devido à sua relevância como principal idioma das bases de dados e periódicos internacionais e o português decorrente da necessidade de se buscar artigos nas bases nacionais; (iv) qualidade dos artigos publicados, sendo selecionados aqueles com maior 
número de citações; (v) artigos empíricos e conceituais; (vi) multidisciplinaridade, contemplando as áreas de negócios, administração, empreendedorismo, sociologia e estudos urbanos, onde o tema de "empreendedorismo imigrante" vem sendo mais estudado por diversos ramos das ciências sociais aplicadas.

A seleção dos artigos seguiu a seguinte sequência:

a) Palavras-chave: foram escolhidas as diretamente relacionadas com os termos "empreendedorismo", "imigrante", "étnico", "immigrant", "entrepreneurship" e "ethnic".

Com estas principais palavras-chave foram utilizados os operadores booleanos - AND, OR, AND, combinados de diferentes formas para modificar o resultado da busca e melhorar seu refino.

b) Busca nas bases ANPAD, Periódicos CAPES, SPELL e Scielo, por artigos acerca do tema empreendedorismo imigrante, com vistas a identificar o status da pesquisa brasileira sobre o assunto. Os artigos encontrados foram quantificados e analisados quanto a sua temática.

c) Pesquisa na base Web of Science para busca de artigos de literatura internacional, através das palavras-chaves e filtros temáticos, para hierarquização de periódicos e identificação dos respectivos fatores de impacto. Além de ser uma base robusta e abrangente, seu uso facilita o tratamento estatístico de número de citações, tanto de autores quanto de artigos. Como será demonstrado que o tema tem início na década de 1980, não foi realizado recorte temporal, sendo considerados artigos publicados em qualquer data.

$\mathrm{Na}$ base Web of Science, o resultado inicial apresentou 906 artigos. Para depurar essa primeira busca, foi utilizada uma filtragem de artigos, assinalando as seguintes áreas de pesquisa: "business economics", "sociology", "geography", "demography", "urban studies" e "social sciences other topics". O objetivo desse procedimento foi o de excluir áreas não correlatas com este estudo. Artigos não disponíveis eletronicamente também foram excluídos (Jones et al. 2011). Como resultado, chegou-se a 676 artigos.

d) Análises quantitativas da base de 676 artigos, envolvendo a identificação do número de artigos publicados por ano, da relação dos 30 periódicos com pelo menos cinco publicações sobre o tema, dos 40 artigos mais citados, dos 20 principais autores e, por fim, a geração das nuvens de palavras a partir dos títulos dos artigos mais antigos (décadas de 1980 e 1990), dos 121 mais recentes, publicados após as revisões bibliométricas de Ma et al. (2013) e Aliaga-Isla e Rialp (2013).

e) Análises qualitativas, com leitura detalhada dos 40 artigos mais citados, para identificação dos principais conceitos e teorias relevantes para o estudo do empreendedorismo imigrante e étnico. Análise das linhas de pesquisa dos 20 autores internacionais que mais publicaram no tema.

Quanto às limitações inerentes ao tema e ao método, foram identificados dois desafios ao presente estudo, que podem ser entendidos como limitações. O primeiro deles refere-se ao próprio contexto do assunto empreendedorismo imigrante, que vem sendo estudado em diversas disciplinas, e muitas vezes é encontrado sob o termo de empreendedorismo étnico ou de minoria, o que inclui os imigrantes (Masurel \& Nijkamp, 2004). O segundo desafio foi lidar com o caráter multidisciplinar do assunto, o que gerou uma necessidade de analisar os artigos selecionados a partir de diferentes perspectivas e paradigmas. Aliaga-Isla e Rialp (2013) destacam limitações semelhantes em seu estudo bibliométrico sobre o tema.

\section{Resultados}

Enfocar em imigrantes significa fazer o recorte do estudo em indivíduos estrangeiros da primeira geração, estabelecidos em determinado país, que não seja o seu de origem. Este conceito difere dos coétnicos, que são os nascidos no país de acolhimento, mas não mais da primeira geração. Adicionalmente a esta definição, os imigrantes são pessoas que estiveram fora do seu país de origem por pelo menos 12 meses (Sasse \& Thielemann, 2005).

\subsection{Empreendedorismo imigrante nas publicações Brasileiras}

O levantamento realizado nas bases de periódicos nacionais ajuda a revelar a lacuna acerca do assunto. Buscando artigos de periódicos revisados por pares no portal da ANPAD (macro-áreas da administração), 
ao se digitar a expressão "imigrante" apareceram apenas sete referências. Destes, os textos efetivamente relacionados ao que se buscava foram encontrados apenas dois estudos de caso sobre imigrantes chineses no Brasil (Carvalho, Silva \& YenTsang, 2015; Oliveira, 2007).

Investigou-se a combinação de duas palavras chaves "empreendedorismo" e "imigrante", ambas em suas formas singulares, utilizando o operador booleano AND nas bases SPELL e CAPES. Na base CAPES resultou em um artigo publicado por Weinberg (2004) na Sæculum - Revista de História.

Já na base SPELL, dos nove artigos encontrados apenas um tangenciava o tema, abordando transnacionalismo e comportamento empreendedor (Oliveira e Iglesias, 2012). Dos que não tinham aderência com o tema foram encontrados cinco artigos relacionados a turismo e sua relação com a colonização de imigrantes europeus e dois outros sem qualquer relação com o tema. O termo "immigrant" no SPELL aponta para quatro artigos, sendo dois relacionados ao tema: o de Oliveira e Iglesias (2012) e outro de Martes e Rodriguez (2004). Desta forma, validou-se a hipótese inicial de que havia pouca produção cientifica no contexto nacional a respeito do tema do empreendedorismo imigrante.

O artigo sobre transnacionalismo e comportamento empreendedor (Oliveira \& Iglesias, 2012), teve como objetivo de ser um estudo exploratório para se verificar uma possível relação entre a conduta dos imigrantes das famílias transnacionais com a de indivíduos empreendedores. Foi realizada uma análise de discurso de um imigrante egípcio residente na Espanha. No entanto os resultados são inconclusivos devido à falta de uma robustez metodológica.

Em Martes e Rodriguez (2004) as relações entre empreendedorismo étnico e religião em comunidades imigrantes norte americanas são discutidas. A análise é feita a partir de entrevistas nas comunidades brasileiras norte americanas e aponta para o fato de que as igrejas protestantes criam um ambiente mais favorável para o empreendedorismo étnico - "teologia da prosperidade", em oposição às igrejas católicas nos Estados Unidos que fomentam a "teologia da libertação". Outra questão interessante levantada, são as dificuldades enfrentadas na pesquisa de campo na obtenção de dados junto a tais grupos, o que poderia explicar o fato de ser uma área menos pesquisadas em administração e empreendedorismo (Raijman, 2001). Portanto, os autores sugerem, já em 2004, que trabalhos futuros deveriam se enfocar no desenvolvimento de formas alternativas para obtenção de dados em populações étnicas imigrantes, e a necessidade expansão do campo.

\subsection{Empreendedorismo étnico nas publicações Brasileiras}

Por se tratar de uma base exclusiva de administração, no mecanismo de busca da ANPAD, utilizando-se apenas o termo "étnico", não se registra nenhum resultado. Na base de periódicos da CAPES a combinação das palavras chaves "empreendedorismo" e "étnico, utilizando o operador booleano AND sugere 10 artigos. Uma análise mais apurada dos referidos textos aponta relevância em apenas dois destes trabalhos: Truzzi e Neto (2007) e Halter (2007), ambos publicados na Revista de Administração de Empresas - RAE. O primeiro refere-se à economia e empreendedorismo étnico à luz da história da imigração paulista. Já o segundo é de um autor estrangeiro convidado, de cunho mais teórico e editorial, a respeito da importância da economia étnica.

Na SPELL a pesquisa por "empreendedorismo" e "étnico, utilizando o operador booleano AND resulta em três artigos, os trabalhos já descritos de Truzzi e Neto (2007) e Martes e Rodriguez, (2004), além de um artigo que tangencia o tema, escrito por Nakahata e Teixeira (2014) sobre a criação de negócios por decasséguis no Paraná.

\subsection{Empreendedorismo imigrante e étnico nas publicações internacionais}

A base de dados Web of Science é atualmente uma das fontes mais robustas de bibliografia cientifico/acadêmica superando um bilhão de referências citadas pesquisáveis em 2015. Dessa forma, optou-se por uma pesquisa inicial ampla dos termos vinculados ao tema. Foi realizada uma busca com a combinação das palavras chaves "immigrant entrepreneurship" e "ethnic", utilizando o operador booleano OR. Como resultado, 906 artigos foram disponibilizados.

Retomando a primeira limitação da pesquisa apresentada na seção de metodologia, optou-se por refinar a busca para as seguintes áreas de pesquisa: "business economics" ou "sociology" ou "geography" 
ou "demography" ou "urban studies" ou "ethnics tudies" ou "social sciences other topics". Essa tratativa sugere 676 artigos que foram devidamente tratados como a amostra inicial de textos do estudo bibliométrico.

A seguir, apresenta-se na Figura 1 a tendência da produção cientifica anual dos referidos artigos.

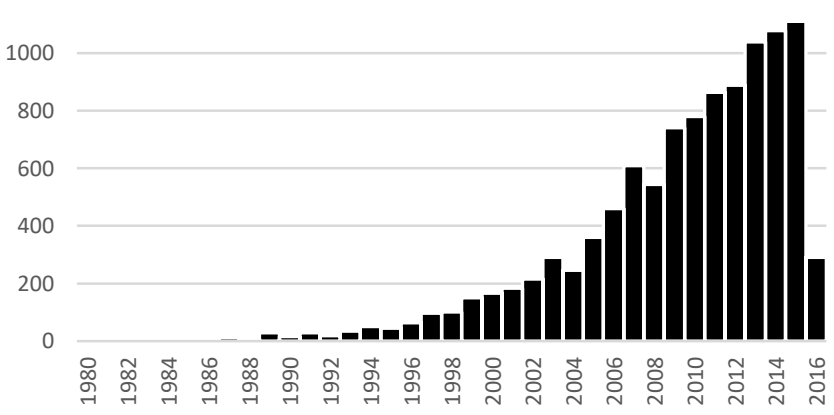

Fig. 1

Quantidade de publicações ao longo dos anos

Fonte: Elaborado pelos autores com base na Web of Science

Conforme se pode observar, mesmo na literatura internacional, o tema empreendedorismo imigrante ou étnico é relativamente novo, se comparado com outros temas da administração. O incremento da produção cientifica se deu a partir dos anos de 1990 de forma consistente.

Utilizando a ferramenta de ranking da própria base de dados, foi gerada a lista de todos os periódicos em que os 676 artigos foram publicados. Assim, foram ordenados os periódicos do maior para o menor número de artigos publicados, sendo os 30 primeiros apresentados na Tabela 1.

Como complemento a essa etapa, utilizou-se o estudo da freqüência de palavras através dos títulos dos 676 artigos publicados. Dos diversos softwares de livre acesso disponíveis na internet para realizar esta tarefa, optou-se pelo da Tagul (www.tagul.com) gerando o resultado apresentado na Tabela 2.
Tab. 1

Quadro de número de artigos nos 30 periódicos com maior número de publicações

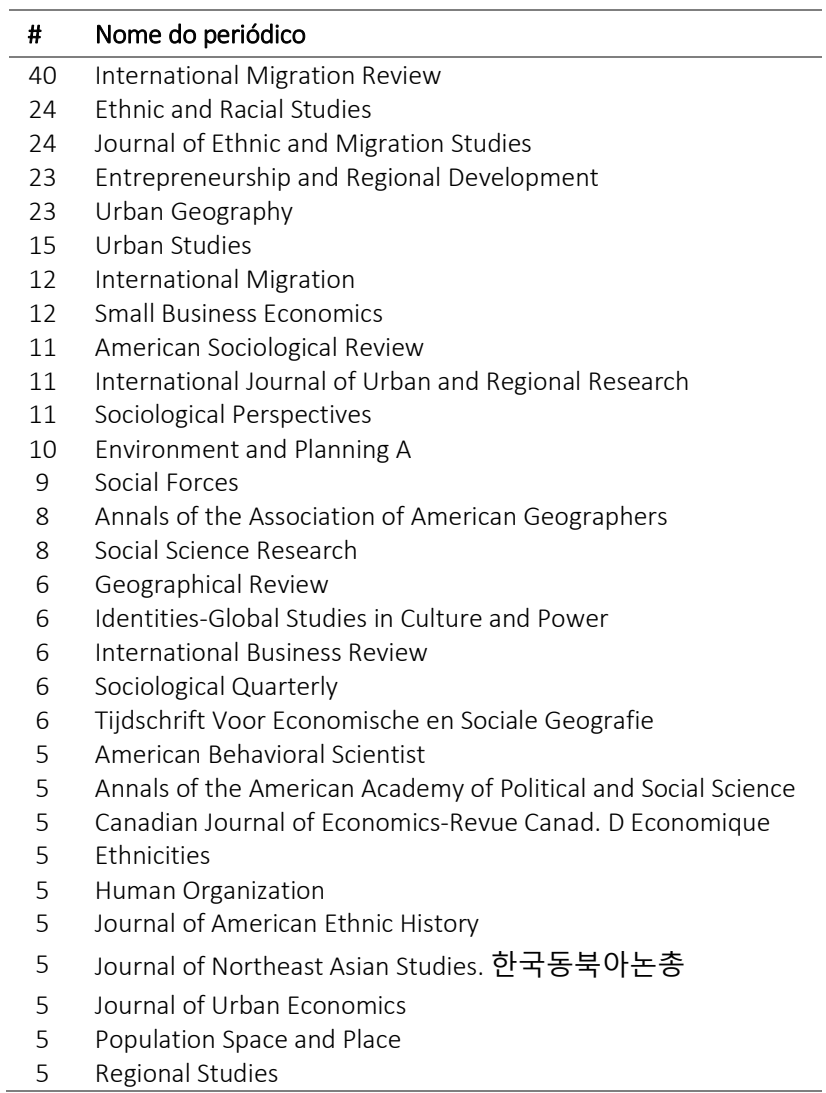

Fonte: Elaborado pelos autores com base na Web of Science

Para uma análise qualitativa buscou-se identificar os 40 artigos mais citados (Tabela 3) e, a partir da leitura destes, extraiu-se os principais conceitos que serão detalhados no item 4.2 deste artigo. Nota-se uma concentração maior nos temas de estudos urbanos, geografia, negócios, recursos humanos e sociologia.

Buscou-se também identificar os autores que mais contribuíram para o desenvolvimento desse campo de estudo, através de suas publicações. Nos 676 artigos que fizeram parte da população total desse

Tab. 2

Frequência de palavras realizada através dos títulos de 676 artigos publicados entre 1980 e 2016.

\begin{tabular}{|c|c|c|c|c|c|c|c|c|c|c|}
\hline$\#$ & Palavras & $\begin{array}{l}1980 \\
2016\end{array}$ & Palavras & $\begin{array}{l}1980 \\
1989\end{array}$ & Palavras & $\begin{array}{l}1990 \\
1999\end{array}$ & Palavras & $\begin{array}{l}2000 \\
2009\end{array}$ & Palavras & $\begin{array}{l}2010 \\
2016\end{array}$ \\
\hline 1 & Ethnic & 278 & Ethnic & 13 & Ethnic & 50 & Ethnic & 113 & Immigrant & 131 \\
\hline 2 & Immigrant & 265 & Enclave & 11 & Immigrant & 28 & Immigrant & 101 & Ethnic & 102 \\
\hline 3 & Entrepreneurship & 16 & Immigrant & 5 & New & 18 & Entrepreneurship & 48 & Entrepreneurship & 48 \\
\hline 4 & Enclave & 105 & Entrepreneurship & 4 & Entrepreneurship & 16 & Enclave & 45 & Enclave & 37 \\
\hline 5 & New & 65 & Economy & 3 & Economy & 13 & Entrepreneurs & 24 & Social & 28 \\
\hline 6 & Employer & 63 & Italian & 3 & Enclave & 12 & Employment & 24 & Employer & 28 \\
\hline 7 & Entrepreneur & 59 & Miami & 2 & Chinese & 12 & Self & 22 & New & 26 \\
\hline 8 & Business & 50 & Case & 2 & Business & 12 & City & 21 & Entrepreneur & 26 \\
\hline 9 & Social & 49 & City & 2 & Employment & 11 & New & 20 & Urban & 24 \\
\hline 10 & City & 48 & Black & 2 & York & 10 & Segregation & 20 & Case & 24 \\
\hline
\end{tabular}

Fonte: Elaborado pelos autores a partir da ferramenta de clusters Tagul.com 
Tab. 3

Artigos mais citados, por número total de citações, ano, periódicos e autores

\begin{tabular}{|c|c|c|c|c|}
\hline Ordem & Total de citações & Ano & Periódico & Autores \\
\hline 1 & 523 & 1997 & IMR & Alba, R; Nee, V \\
\hline 2 & 285 & 2002 & ASR & Logan, JR; Alba, RD; Zhang, WQ \\
\hline 3 & 268 & 2002 & ASR & Portes, A; Haller, WJ; Guarnizo, LE \\
\hline 4 & 248 & 1996 & ASR & Sanders, JM; Nee, V \\
\hline 5 & 245 & 1998 & IMR & Levitt, $\mathrm{P}$ \\
\hline 6 & 243 & 1987 & ASR & Sanders, JM; NEE, V \\
\hline 7 & 238 & 1993 & AJS & Alba, RD; Logan, JR \\
\hline 8 & 216 & 1989 & ASR & Portes, A; Jensen, L \\
\hline 9 & 169 & 1996 & $J H R$ & Fairlie, RW; Meyer, BD \\
\hline 10 & 160 & 2003 & QJE & Edin, PA; Fredriksson, $\mathrm{P}$; Aslund, $\mathrm{O}$ \\
\hline 11 & 146 & 2004 & IMR & Zhou, M \\
\hline 12 & 138 & 1982 & AJS & Wilson, KL; Martin, WA \\
\hline 13 & 132 & 1994 & IMR & Portes, A; Schauffler, R \\
\hline 14 & 121 & 1992 & ERS & Portes, A; Zhou, M \\
\hline 15 & 113 & 2004 & SSR & Iceland, J \\
\hline 16 & 110 & 1995 & ERS & Waldinger, $\mathrm{R}$ \\
\hline 17 & 110 & 1994 & SF & Logan, JR; Alba, RD; Mcnulty, TL \\
\hline 18 & 109 & 1987 & ASR & Portes, $A$; Jensen, $L$ \\
\hline 19 & 107 & 1996 & ASR & Portes, A; Zhou, M \\
\hline 20 & 100 & 2001 & ERS & Nee, V; Sanders, J \\
\hline 21 & 99 & 1996 & US & Barrett, GA; Jones, TP; McEvoy, D \\
\hline 22 & 97 & 1994 & ASR & Nee, V; Sanders, JM; Sernau, S \\
\hline 23 & 95 & 2004 & AAAG & Ellis, M; Wright, R; Parks, V \\
\hline 24 & 86 & 2006 & US & Atkinson, $R$ \\
\hline 25 & 85 & 2002 & US & Johnston, R; Forrest, J; Poulsen, M \\
\hline 26 & 83 & 1989 & ASR & Evans, MDR \\
\hline 27 & 83 & 1995 & ARS & Waters, MC; Eschbach, $\mathrm{K}$ \\
\hline 28 & 83 & 2000 & LE & Clark, K; Drinkwater, S \\
\hline 29 & 82 & 1994 & SP & Light, I; Sabagh, G; Bozorgmehr, M; Dermartirosian, C \\
\hline 30 & 80 & 2002 & ARS & Sanders, JM \\
\hline 31 & 76 & 2007 & AAAG & Johnston, Ron; Poulsen, Michael; Forrest, James \\
\hline 32 & 73 & 2003 & RS & Nijkamp, P \\
\hline 33 & 68 & 2000 & IMR & Rath, J; Kloosterman, R \\
\hline 34 & 65 & 2005 & AMJ & Dobrev, SD; Barnett, WP \\
\hline 35 & 65 & 1998 & SBE & Basu, A \\
\hline 36 & 64 & 2006 & $\mathrm{CJE}$ & Walks, R. Alan; Bourne, Larry S. \\
\hline 37 & 62 & 1991 & GS & Loscocco, KA; Robinson, J \\
\hline 38 & 62 & 2003 & IMR & Logan, JR; Alba, RD; Stults, BJ \\
\hline 39 & 62 & 2008 & JES & Van der Sluis, Justin; van Praag, Mirjam; Vijverberg, Wim \\
\hline 40 & 52 & 1993 & IJURS & Waldinger, $\mathrm{R}$ \\
\hline
\end{tabular}

Fonte: Elaborado pelos autores a partir da ferramenta de clusters Tagul.com

Legenda: AJS: American Journal of Sociology, JHR: Journal of Human Resources, QJE: Quarterly Journal of Economics, LE: Labour Economics, AMJ: Academy of Management Journal, GS: Gender \& Society, e JES: Journal of Economic Surveys.,

estudo bibliométrico, foram registrados, ao todo, 939 autores. Destes, 84,7\% ou 796 pesquisadores, contribuíram com apenas um trabalho sobre o tema, isso denota que o campo é emergente e ainda pulverizado, talvez por sua característica multidisciplinar.

Essa interpretação ganha força quando se verifica que apenas 20autores participaram em cinco ou mais trabalhos dentre da base pesquisada, o que se apresenta na Tabela 4.

\subsection{Primeiros estudos}

Com relação às primeiras publicações que surgiram em periódicos internacionais, identificou-se que elas datam dos anos 1980, e enfocavam, sobretudo, os enclaves étnicos, indo gradativamente para uma perspectiva de empreendedorismo em si, conforme a Tabela 5. No início, o campo emergiu de estudos sociológicos, o que pode ser corroborado ao se analisar os periódicos das primeiras publicações.

Os periódicos distribuíam-se em periódicos de sociologia, estudos étnicos e migração: AJS, ASR, IMR, JAEH, JDA, JES, JUH, SP e UE.

Utilizando-se o estudo da frequência de palavras dos títulos de 112 artigos publicados nas décadas de 1980 e 1990 foi gerado um resultado que indica os temas mais recorrentes. 
Tab. 4

Autores com o maior número de contribuições publicadas

\begin{tabular}{|c|c|c|c|c|}
\hline$\# \mathrm{~N}$ & Nome & País & Universidade Departamento & Principais assuntos \\
\hline 18 & Johnston, Ron & Reino Unido & $\begin{array}{l}\text { Faculdade de Ciências Geográficas } \\
\text { da Universidade de Bristol }\end{array}$ & \multirow{3}{*}{$\begin{array}{l}\text { Segregação étnica, assimilação } \\
\text { cultural e enclaves étnicos }\end{array}$} \\
\hline 15 & Forrest, James & \multirow{2}{*}{ Austrália } & Departamento de Geografia & \\
\hline 14 & Poulsen, Michael & & Humana da Macquarie University & \\
\hline 11 & Kwon, Seok-Woo & EUA & $\begin{array}{l}\text { Departamento de Gestão } \\
\text { Estratégica da Fox School of } \\
\text { Business na Temple University }\end{array}$ & Capital social entre imigrantes \\
\hline 9 & Boyd, Robert L. & EUA & $\begin{array}{c}\text { Professor de sociologia na Mississipi } \\
\text { State Univertity }\end{array}$ & Economias étnicas, Varejo entre imigrantes \\
\hline 8 & Alba, Richard D & EUA & $\begin{array}{l}\text { Distinguished Professor do } \\
\text { Graduate Center } \\
\text { Universidade de Nova York }\end{array}$ & $\begin{array}{l}\text { Desenvolveu a teoria de assimilação para se } \\
\text { ajustar à era contemporânea, multi-racial da } \\
\text { imigração, com estudos na América, França e } \\
\text { Alemanha. }\end{array}$ \\
\hline 8 & Wang, Qingfang & EUA & $\begin{array}{l}\text { Professora de política pública na } \\
\text { Universidade da Califórnia - } \\
\text { Riverside. }\end{array}$ & $\begin{array}{l}\text { Imigração, raça / etnia, empreendedorismo e } \\
\text { migração transnacional }\end{array}$ \\
\hline 7 & Fong, Eric & Canadá & $\begin{array}{l}\text { Professor de Sociologia da } \\
\text { Universidade de Toronto }\end{array}$ & $\begin{array}{c}\text { Examina atualmente as empresas de imigrantes } \\
\text { em pequenas e grandes cidades. }\end{array}$ \\
\hline 7 & Logan, JR & EUA & $\begin{array}{l}\text { Departmento de Sociologia da } \\
\text { Universidade de Albany - NY }\end{array}$ & $\begin{array}{l}\text { Economias étnicas e imigrantes em grandes } \\
\text { cidades: Miami, NY e Los Angeles }\end{array}$ \\
\hline 7 & Portes, Alejandro & EUA & $\begin{array}{l}\text { Dep. de Sociologia, } \\
\text { Univerdidsade de Princeton }\end{array}$ & $\begin{array}{l}\text { Empreendedorismo imigrante, enclaves étnicos, } \\
\text { capital social e mobilidade econômica. }\end{array}$ \\
\hline 7 & Zhou, M & EUA & $\begin{array}{l}\text { Professora de Sociologia e estudos } \\
\text { do Asian American na UCLA }\end{array}$ & $\begin{array}{l}\text { Migração internacional, relações étnicas e raciais } \\
\text { e empreenddorismo imigrante }\end{array}$ \\
\hline 6 & Nijkamp, Peter & Holanda & $\begin{array}{l}\text { Prof.de Econômia Regional e } \\
\text { Urbana e Geografia Economica na } \\
\text { VU University - Amsterdam }\end{array}$ & Empresários étnicos e economia urbana \\
\hline 5 & Chen, Wenhong & EUA & Universidade do Texas & Capital social, redes sociais e empreendedorismo \\
\hline 5 & Clark, Ken & Reino Unido & $\begin{array}{l}\text { Escola de Economia da } \\
\text { Univ. de Manchester }\end{array}$ & Migração e auto-emprego no Reino Unido \\
\hline 5 & Li, Peter S. & Canadá & $\begin{array}{l}\text { Professor de sociologia } \\
\text { Univ. de Saskatchewan }\end{array}$ & Raca e etinia, imigração, chineses no Canadá \\
\hline 5 & Light, Ivan & EUA & $\begin{array}{c}\text { Prof. Emérito } \\
\text { Dept. de Sociologia - UCLA }\end{array}$ & Imigração, empreendedores e sociologia urbana \\
\hline 5 & Liu, Cathy Yang & EUA & $\begin{array}{l}\text { Escola de Estudos Políticos } \\
\text { Univ. Estadual da Georgia }\end{array}$ & Segregação étnica, empreendedorismo étnico \\
\hline 5 & Nee, Victor & EUA & $\begin{array}{l}\text { Deptartamento de Sociologia } \\
\text { Cornell University }\end{array}$ & $\begin{array}{l}\text { Sociologia econômica, papel das redes e normas } \\
\text { nas instituições econômicas e organizações. }\end{array}$ \\
\hline 5 & Razin, Eran & Israel & $\begin{array}{l}\text { Dept. de Geografia - Hebrew } \\
\text { University of Jerusalem }\end{array}$ & Empreenddores étnicos nos EUA e Canadá \\
\hline 5 & Sanders, JM & EUA & $\begin{array}{l}\text { Prof. de Sociologia } \\
\text { Univ. da Carolina do Sul }\end{array}$ & Capital social e humano e solidariedade limitada. \\
\hline
\end{tabular}

Fonte: Elaborado pelos autores a partir da ferramenta de busca Web of Science

Tab. 5

Primeiros estudos em empreendedorismo imigrante/étnico

\begin{tabular}{|c|c|c|}
\hline Ano & Título & Autores \\
\hline 1982 & Ethnic Enclaves: A Comparison of the Cuban and Black Economies in Miami & Wilson, Kl; Martin, Wa \\
\hline 1983 & Ethnics and Enclaves - Bostons Italian North-End - Demarco,WM & Briggs, Jw \\
\hline 1984 & $\begin{array}{l}\text { Forward and Backward Linkages in a Plantation Economy - Immigrant Entrepreneurship and Industrial- } \\
\text { Development in Yucatan, Mexico }\end{array}$ & $\begin{array}{l}\text { Baklanoff, En; Brannon, } \\
\text { Jt }\end{array}$ \\
\hline 1985 & A Comparative Perspective on the Ethnic Enclave - Blacks, Italians, and Jews in New-York-City & Model, S \\
\hline 1985 & Ethnics and Enclaves - Bostons Italian North-End - Demarco,WM & Baily, SI \\
\hline 1987 & Ethnic Enclaves and Middleman Minorities - Alternative Strategies of Immigrant Adaptation & Cobas, Ja \\
\hline 1987 & Does Self-Esteem Affect Educational Aspirations - The Case of the Ethnic Enclave & Yogev, A; Ilan, Y \\
\hline 1987 & $\begin{array}{l}\text { Women, Work and Ethnic-Identity - Personal Narratives and the Ethnic Enclave in the Textile City of Lowell, } \\
\text { Massachusetts }\end{array}$ & Norkunas, Mk \\
\hline 1987 & Making It in America - a Social Evaluation of the Ethics of Immigrant Entrepreneurship & Bonacich, E \\
\hline 1987 & Limits of Ethnic Solidarity in the Enclave Economy & Sanders, Jm; Nee, V \\
\hline
\end{tabular}

Fonte: Elaborado pelos autores a partir da ferramenta de busca Web of Science 
Tab. 6

Frequência de palavras realizada através dos títulos de 112 artigos publicados nas décadas de 1980 e 1990

\begin{tabular}{lc}
\hline PALAVRA & 1980 a 1990 \\
\hline Ethnic & 63 \\
Immigrant & 33 \\
Enclave & 23 \\
Entrepreneurship & 20 \\
New & 19 \\
Economy & 16 \\
Chinese & 12 \\
Business & 12 \\
Employment & 11 \\
York & 11 \\
\hline
\end{tabular}

Fonte: Elaborado pelos autores a partir da ferramenta de clusters Tagul.com

Uma revisão dos resumos dos artigos sugere que o debate acerca do empreendedorismo de imigrantes, nasce como uma decorrência dos estudos étnicos. Uma avaliação da frequência de palavras indica uma presença tímida do termo empreendedorismo (entrepreneurship). Outro destaque diz respeito as áreas geográficas ou grupos étnicos inicialmente pesquisados: chineses, cubanos, asiáticos, Nova York e Los Angeles.

\section{Discussão}

4.1 Principais temas discutidos nos artigos seminais

A intenção desta seção é a de contextualizar os diversos temas ou trabalhos seminais que influenciaram direta ou indiretamente o tema do empreendedorismo imigrante. Primeiramente são apresentados alguns trabalhos seminais de internacionalização de negócios, em seguida a teoria dos tipos de capitais, do empreendedorismo imigrante, do transnacionalismo e do enclave étnico. Para tal, foram utilizados os 40 artigos mais citados na base pesquisada.

\subsubsection{Teoria da assimilação e auto-emprego}

O artigo seminal de Portes e Zhou (1992) procura demonstrar como a saída do enclave e assimilação cultural de co-étnicos pode ter um efeito negativo para os ganhos deste grupo, já que eles, ao deixarem os enclaves, não mais usufruem das redes de capital social, engajando-se na disputa por empregos em um mercado aberto e competitivo. Os autores pesquisam sua hipótese e comparam diversas comunidades étnicas. Posteriormente, Portes e Zhou (1996) também examinam a questão dos retornos econômicos dos imigrantes envolvidos em 'autoemprego'.
Já o artigo de Evans e Leighton (1989) discute por que alguns grupos de imigrantes são mais propícios a empreender do que outros na Austrália. Baseado na ecologia organizacional, o autor argumenta que um determinado grupo de imigrantes atua como um nicho econômico para pequenas empresas. Grupos maiores grandes proporcionam um nicho ainda mais favorável para os empresários étnicos. A fluência menor na língua local também pode configurar nichos étnicos mais fechados, nos quais os empregados co-étnicos são melhor aceitos.

Alba e Logan (1993) analisam dois modelos teóricos complementares assimilação espacial e estratificação por localização. Os pesquisadores aplicam seu estudo em comunidades suburbanas de Nova York, a partir de 1980. Embora haja menos segregação nos subúrbios do que nas regiões centrais das cidades, os autores encontraram diferenças marcantes entre os grupos raciais/étnicos quanto ao nível de segregação de brancos não-hispânicos e negros. Já Alba e Nee (1997), apresentam a teoria da assimilação e aculturação dos imigrantes, e propõem uma revisão dos conceitos de Gordon (1964) para suprir lacunas de causalidade, sendo este o artigo mais citado de toda amostragem do assunto. A questão étnica e desigualdades também são abordadas por Waters e Eschbach (1995).

Fairlie e Meyer (1996) demonstram evidências de que as taxas de auto-emprego diferem substancialmente entre os 60 grupos étnicos e raciais nos Estados Unidos, e traçam hipóteses de associação positiva entre a taxa de auto-emprego de um grupo étnico/racial e a diferença entre a média de ganhos deste grupo no 'auto-emprego' ou através de emprego assalariado. Apesar do que poderia se supor, de que a discriminação e as dificuldades em apreender a língua local levariam ao aumento do 'auto-emprego', na realidade, em muitos casos são os ganhos econômicos o principal fator decisivo de se engajar em atividades empreendedoras, segundo os autores. Este estudo é complementado pelo de Clark e Drinkwater (2000) no Reino Unido. Já mais recentemente, pesquisas incluindo grupos como os cubanos em Miami, os afro-americanos, portoriquenhos, coreanos, dominicanos, chineses, mexicanos e salvadorenhos divergem em relação à possível associação positiva entre a taxa de 'autoemprego' e o sucesso econômico de um grupo étnico (Logan, Alba, Stults, 2003). 
Além da discussão do empreendedorismo ou 'autoemprego' como mecanismo de sobrevivência para determinadas etnias, a questão de gênero no empreendedorismo, é debatida por Loscocco e Robinson (1991). No entanto, alguns fatores fazem com que as pequenas empresas pertencentes a mulheres tendam a ser menos bem-sucedidas do que aquelas possuídas por homens, o que é abordado pelos autores.

Por outro lado, o estudo de Nee, Sanders e Sernau (1994) aponta para uma tendência de alguns imigrantes se afastarem dos sub-empregos da economia étnica mais informal, buscando trabalho formais fora do enclave.

Barrett, Jones e McEvoy (1996) concentram-se em seu estudo no tema do empreendedorismo de minorias étnicas na Grã-Bretanha e América do Norte. Os autores evidenciam altas taxas de 'autoemprego', entre 11 e 14,9\% para certos grupos étnicos minoritários e os mecanismos de promoção de negócios destas minorias.

Já Iceland (2004) pesquisa as tendências da segregação residencial racial e étnica através nos Estados Unidos no período de 1980-2000, confirmando através de análises estatísticas que a diversidade aumentou, embora a segregação pouco tenha mudado. Outro artigo, de Johnston, Poulsen e Forrest (2007) aborda a segregação residencial geográfica, através de um estudo comparativo de cinco países de língua inglesa.

\subsubsection{Enclaves étnicos}

Logan, Zhang e Alba (2002) em seu artigo apontam para a afluência de grupos étnicos que saem do enclave étnico para habitar bairros dos subúrbios tradicionalmente dominados pela população branca norte americana. Os autores estudam quinze grupos étnicos de bairros com concentração nas cidades de Nova lorque e Los Angeles demonstrando seus padrões de localização espacial e variáveis que influenciam a escolha do local de moradia. Os autores evidenciam que a escolha da localização do enclave não está somente relacionada com restrições financeiras. Enquanto para alguns grupos o enclave pode ser um destino visando maior assimilação, para outros seria apenas um local temporário, até as condições financeiras melhorarem.

Wilson e Martin (1982) evidenciam a vantagem relativa de certos enclaves étnicos ao realizarem uma análise comparativa das empresas cubanas e de negros em Miami, sugerindo que o enclave cubano é o mais favorecido, sendo caracterizado por indústrias altamente interdependentes.

No artigo de Sanders e Nee (1987) evidenciam também os mecanismos de adaptação social e econômica dos imigrantes à vida nos Estados Unidos, tocando na questão da solidariedade étnica. Segundo os autores, Portes e outros pesquisadores avançaram na hipótese da 'economia de enclave', que contradiz a visão clássica da assimilação na qual a segregação retardaria o progresso econômico e mobilidade social das minorias. Os autores, ao analisarem imigrantes cubanos e chineses, sugerem que a hipótese clássica do enclave é suportada apenas no caso dos empresários, mas a perspectiva de assimilação explica melhor o aumento dos ganhos dos trabalhadores que estão empregados fora do enclave, o que evidencia diferenças entre ganhos e assimilação dos 'imigrantes-trabalhadores' e 'imigrantes-chefes'.

Portes e Jensen (1989) debatem sobre quatro hipóteses a respeito das características e as consequências da participação em uma economia de enclave étnico: a primeira com base no local de residência, a segunda e terceira relativa aos efeitos da participação em uma economia étnica para empresários e trabalhadores, e a quarta teoria sobre os determinantes do 'auto-emprego' entre as minorias étnicas. Resultados consistentes contradizem o conceito de empresas étnicas como veículos para a exploração de mão de obra e dos enclaves como meras aglomerações residenciais, demonstrando a ascensão de uma minoria empresarial e a influência da estrutura familiar e do gênero feminino no estabelecimento de empresas étnicas.

Waldinger (1993) revisita o tema do enclave étnico fazendo referências aos trabalhos seminais de Alejandro Portes a respeito dos cubanos de Miami.

Portes e Schauffler (1994) apontam para a formação de enclaves linguísticos em várias cidades norte-americanas, explorando a extensão da transição linguagem e da resiliência das línguas de imigrantes com base em dados do sul da Flórida.

Segundo Light, Sabagh, Bozorgmehr, e DerMarirosian (1994), os termos 'economia étnica' e 'economia de enclave étnico' designam negócios imigrantes, de minorias étnicas, ou mesmo o setor de 
emprego que coexiste com o mercado local. Apesar de muitas vezes serem tratados como sinônimos, os autores esclarecem que o conceito de 'economia de enclave étnico' deriva da literatura segmentação laboral, ao passo que o conceito de economia étnica deriva da literatura minorias intermediárias. Destes conceitos surge também um intenso debate sobre os salários de trabalhadores do enclave étnico versus da economia geral.

Logan, Alba, e McNulty (1994) examinam também a situação no mercado étnico em dezessete áreas metropolitanas. Cinco grupos asiáticos (japoneses, chineses, coreanos, filipinos e indianos asiáticos) e três grupos hispânicos (cubanos, mexicanos e portoriquenhos) são comparados aos brancos nãohispânicos e negros. Os autores apontam para concentrações empresariais de minorias principalmente em setores com baixos salários, baixa capitalização, baixos níveis de sindicalização, e proporções elevadas de trabalhadores do sexo feminino. Os enclaves baseiam-se em uma combinação de fabricação de roupas e alimentos étnicos.

Waldinger (1995) aponta para o interesse crescente na pesquisa de atividades empreendedoras das diferentes etnias. Segundo o autor,a inserção de um negócio dentre de uma rede ou comunidade étnica leva a cooperação entre os agentes econômicos étnicos, impedindo o acesso a estranhos.

Outro estudo interessante e também muito citado dos pesquisadores escandinavos (Åslund, Edin \& Fredriksson, 2001), que analisam a política pública sueca de dispersão de imigrantes refugiados, como um experimento natural, apresentando evidências de que os que vivem em enclaves melhoram seus ganhos.

Zhou (2004) revisita as teorias e conceitos de empreendedorismo étnico dos últimos trinta anos, primeiro, ela reexamina o significado de minorias intermediárias, economia étnica e economia de enclave, argumentando que devem ser pesquisadas as estruturas étnicas sociais em que os empresários estão embutidos. A autora aponta para convergências e controvérsias na investigação sobre o empreendedorismo, suas causas e consequências, e destaca também dois avanços conceituais interrelacionados no estudo do empreendedorismo étnico: do transnacionalismo versus empreendedorismo e a sinergia do empreendedorismo com a construção de uma comunidade.

A questão espacial da concentração de determinados grupos étnicos também é abordada por alguns estudos britânicos como os de Atkinson (2006) e de Ellis, Wright e Parks (2004). Enquanto o primeiro busca explicações da segregação em fatores diferentes da renda, como a discriminação social e institucional. O segundo apresenta uma perspectiva diferente, desvendando uma falsa impressão dos espaços étnicos, que são tidos como fixos em uma cidade, caracterizando erroneamente bairros como o domínio daqueles que vivem, em vez dos que trabalham neles. Outros estudos discutem a segregação residencial dos grupos étnicos em áreas urbanas, como importante questão para a formulação de políticas em sociedades multiculturais como a inglesa (Johnston, Forrest \& Poulsen, 2002) e a canadense (Walks \& Bourne, 2006).

\subsubsection{Transnacionalismo}

Portes, Guarnizo e Haller (2002) discutem o transnacionalismo imigrante como uma forma alternativa de adaptação econômica de minorias étnicas nas sociedades, baseada no uso suas redes sociais transnacionais. Segundo os autores, embora o transnacionalismo imigrante tenha recebido pouca atenção na literatura sociológica dominante até agora, ele tem o potencial de alterar o caráter das novas comunidades étnicas geradas pela imigração contemporânea. Esta existência empírica do transnacionalismo é examinada pelos autores com base nas características discriminantes dos imigrantes e as probabilidades relativas deles se envolverem nesses tipos de atividades.

\subsubsection{Teorias dos capitais e sua influência na formação das comunidades imigrantes}

Outra dimensão interessante a ser analisada na esfera do empreendedorismo são os 'tipos de capital' presentes: o 'capital econômico', o 'capital humano' e o 'capital social', (Bourdieu, 2011). A noção de 'capital econômico' é bem conhecida e está relacionado aos recursos financeiros para se constituir uma empresa e sua origem: própria ou de terceiros. No entanto em enclaves étnicos nota-se a presença de uma série de mecanismos alternativos de financiamento como nos estudos de Portes e Zhou (1992) e Basu (1998). 
Já, o capital humano refere-se a investimentos em educação, experiências profissionais ou habilidades de trabalho (Becker, 1964). Portanto esta dimensão pode ser expressa tanto pelo nível de escolaridade quanto pelos conhecimentos adquiridos de experiências de trabalhos anteriores, ou até de cunho empresarial.

O capital social, por sua vez, segundo Ndofor e Priem (2011), está ligado à rede profissional (network) do empreendedor imigrante, incluindo outros empresários, fornecedores, prestadores de serviços e até mesmo concorrentes. Esta será a dimensão mais explorada e detalhada a seguir.

Segundo Martes e Rodriguez (2004) diversos autores sugerem que um dos recursos mais importantes que as comunidades étnicas e imigrantes possuem é seu capital social, não raro associado às taxas mais elevadas de sucesso de seus negócios (Light, 1972; Light \& Bonacich, 1988; Portes, 1987; Putnam, Leonardi \& Nanetti, 1993). Ainda segundo Martes e Rodriguez (2004) e Light (1998), esta relação primordial entre capital social e o empreendedorismo étnico acontece devido ao uso de alguns elementos do capital social, tais como a solidariedade, valores éticos e culturais, conhecimentos e habilidades. Os empreendedores étnicos minimizam seus riscos construindo mecanismos de cooperação, mesmo que alguns casos compitam entre si. Estes seriam a confiança reforçada entre os indivíduos de mesma etnia (Portes \& Sensenbrenner, 1993) e a possibilidade de explorar um mercado consumidor particular, com acesso privilegiado a matérias primas e aos trabalhadores étnicos.

Sanders e Nee (1996) examinam como o autoemprego entre os imigrantes asiáticos e latinoamericanos é afetado pela composição da família e dos recursos de capital humano, sendo que os interesses coletivos e os fortes laços familiares facilitam a alavacagem de recursos. Imigrantes empreendedores recorrem a esses recursos na criação e operação de suas pequenas empresas. Posteriormente, os autores realizam outro estudo (Nee \& Sanders, 2001), desenvolvendo um modelo de incorporação de imigrantes baseado nos tipos de capital, que estabelece a maneira pela qual o capital social, financeiro e humano-cultural das famílias imigrantes geram possíveis trajetórias do mercado de trabalho. Por exemplo, os imigrantes que chegam com baixos estoques de capital financeiro e capital cultural são mais propensos a se empregarem na economia étnica, enquanto que imigrantes com capital humano-cultural mais alto tem a possibilidade de obterem um emprego na economia formal. A pesquisa é baseada em um estudo de campo de imigrantes asiáticos na área de Los Angeles. Em Sanders (2002), o autor vai além da questão do uso de capital social derivado das redes e identidade étnica e enfoca em como essas redes interpessoais, presentes no seio das comunidades étnicas, influenciam seu grau de enclausuramento e de sua identidade étnica.

Este debate é complementado pelo trabalho de Basu (1998), onde o autor discute o estabelecimento de pequenos negócios asiáticos na Grã-Bretanha, por parte de empresários bem-educados, mas com grande espírito empreendedor. Este aponta para o papel potencial dos bancos e agências governamentais no sentido de incentivar a criação destas pequenas empresas no país.

Levitt (1998) endereça, em seu estudo, a questão das ditas 'remessas sociais', uma forma de difusão cultural relacionada com a migração: ideias, comportamentos, identidades e capital social, os quais decorrem da relação entre as comunidades receptoras e dos países de envio, sendo que estes recursos têm um papel reconhecido para o empreendedorismo imigrante e na transformação de comunidades locais.

Nijcamp (2003), numa perspectiva mais abrangente a respeito do empreendedorismo, apresenta a evidência das áreas urbanas como local favorável para a incubação de empreendimentos inovadores, resultado da densidade econômica e das oportunidades criadas pela cidade. Embora as redes informais entre negócios, a exemplo dos nichos étnicos, possam ser favoráveis para o desempenho econômico, segundo o autor, o moderno empreendedor tende a se tornar cada vez mais um operador e gestor de uma rede criativa. Já Dobrev e Barnett (2005) estudam como o papel individual do empreendedor influencia o estabelecimento do negócio, quer acelerando ou retardando o processo de empreender.

Em relação ao impacto da educação no empreendedorismo, no estudo de Van der Sluis, Van Praag \& Vijverberg (2008) é evidenciado um efeito positivo e significativo. No entanto, os autores apontam para efeitos menores nos rendimentos de empreendedores europeus do que nos dos EUA, mais 
elevados para as mulheres do que para homens, e menores para os não-brancos ou imigrantes.

\section{Considerações}

Relembrando que o objetivo do presente estudo foi o de contribuir com a expansão das pesquisas sobre empreendedorismo realizado por imigrantes, inspirando novos caminhos de investigação, apresentam-se as seguintes observações.

Através de uma análise bibliométrica geral de temas abordados e da frequência de palavras para os 676 artigos pesquisados, nota-se que o tema do empreendedorismo imigrante possui uma forte dependência em teorias sociológicas. Isto pode ser evidenciado por pelo menos três fatores identificados no corpo do trabalho: pela análise dos temas pesquisados, pela listagem dos periódicos onde há maior número de publicações, ou dos que contém os trabalhos mais citados. No entanto, dado a seu caráter multidisciplinar, surgem oportunidades nas diversas macro áreas da administração: organizações, estratégia, recursos humanos e marketing contribuírem com a discussão do tema. 0 avanço experimentado nos últimos anos pela ciência da administração pode agregar valor não só acadêmico quanto gerencial aos estudos apresentados até aqui.

No caso do presente artigo, dada a pouca pesquisa nacional acerca do tema, a contribuição acadêmica se faz presente na apresentação do debate dos diversos estudos internacionais, que podem vir a subsidiar pesquisas com comunidades imigrantes brasileiras ou comunidades de imigrantes no Brasil. Neste tocante, destaca-se que o presente estudo atualiza os trabalhos de Aliaga-Isla e Rialp (2013) e Ma et al. (2013), além de agregar uma análise da literatura acadêmica nacional.

A respeito da contribuição gerencial, é preciso pontuar que a comunidade brasileira no exterior ainda experimenta suas primeiras décadas de ocupação. Assim, através de uma comparação com outras comunidades imigrantes ou étnicas é possível vislumbrar caminhos para empreendedorismo, a gestão de pequenos negócios no exterior ou mesmo de indicação de políticas públicas internacionais.

Acerca da questão da localização geográfica dos estudos, como é demonstrado por Aliaga-Isla e Rialp (2013), grande parte dos artigos têm-se centrado em países desenvolvidos. Contudo, a imigração ocorre em outros contextos, movendo-se para as economias emergentes. Isso inclui fluxos de imigrantes oriundos de países desenvolvidos migrando para países emergentes e também de um país emergente para outro, o que representam oportunidades novas de pesquisa.

Mesmo em se tratando do contexto de estudos de comunidades imigrantes conduzidos em sua maioria nos países desenvolvidos, esta revisão aponta para uma predominância de pesquisas no contexto norteamericano, e menor no contexto europeu. Dado o crescente fluxo migratório de refugiados para Europa esta questão se torna premente.

Propõe-se que se estudem também as populações latino-americanas, mais especificamente as brasileiras, na Europa, mesmo sabendo que o foco no momento sejam os refugiados provenientes de países africanos e do Oriente Médio.

Nota-se que, em geral, os trabalhos realizados enfocaram em comunidades específicas de imigrantes. A comunidade asiática parece ser relevante para a Grã-Bretanha, Estados Unidos, Canadá e Austrália. Já as comunidades latinoamericanas têm mais importância no contexto norteamericano e espanhol, por exemplo. Portanto, a literatura também carece de estudos comparativos, que proporcionariam uma compreensão mais ampla do fenômeno, corroborando com a lacuna identificada por Aliaga-Isla e Rialp (2013).

Estes estudos comparativos podem estar relacionados tanto ao fenômeno do empreendedorismo em si (Johnston, Poulsen \& Forrest, 2007; Portes \& Zhou, 1992), quanto os voltados para a comparação de políticas, sejam promotoras ou restritivas, do empreendedorismo imigrante em países específicos tais como Austrália (Collins, 2003), Holanda (Kloosterman, 2003) e Alemanha (Kontos, 2003).

Faz-se necessário cada vez mais pesquisar aspectos mais diretamente ligados ao empreendedorismo e ao capital humano. O primeiro deles seria relativo ao papel que o conhecimento prévio - seja através da escolaridade ou de experiências profissionais- exerce sobre os negócios imigrantes no processo de reconhecimento de oportunidades, para cada uma das diversas etnias e diversos contextos locais. Outro seria a investigação de como os traços de uma cultura nacional podem 
influenciar na criação de oportunidades empreendedoras.

Visando a identificação de temas emergentes, buscou-se, na mesma base de artigos, identificar todos aqueles publicados após os dois estudos bibliométricos citados. Foram encontrados 183 trabalhos no período entre 2013 e 2016 cuja maior frequência de palavras se deve aos termos "imigrante", que aparece 75 vezes, e "étnico" apenas 58 vezes. Se comparado à freqüência dos 493 artigos até o final do ano de 2012 o termo "imigrante" apareceu 190 vezes e o termo "étnico" 220 vezes.

Torna-se estratégico, portanto, para expandir este campo na linha de pesquisa de empreendedorismo internacional no Brasil, a colaboração dos mais diversos estudiosos brasileiros, através de perspectivas da gestão, estratégias, mercados, comportamento de consumo, economias étnicas, dentre outros possíveis temas de pesquisa. Complementarmente, sugere-se o desenvolvimento de linhas de pesquisa referentes à antropologia do empreendedor imigrante, estudos de marketing ligados ao comportamento do consumidor étnico e mercados étnicos, netnografia dos empreendedores imigrantes, entre outros. Conclui-se este artigo convidando demais acadêmicos e pares destas áreas a colaborarem com estudos futuros.

\section{Referências}

- Acs, Z. J., Audretsch, D. B., \& Evans, D. S. (1994). Why does the self-employment rate vary across countries and over time? $\left(\mathrm{n}^{\circ} 871\right)$. CEPR Discussion Papers.

- Alba, R. D., \& Logan, J. R. (1993). Minority proximity to whites in suburbs: An individual-level analysis of segregation. American journal of sociology, 98 (6), 1388-1427.

- Alba, R., \& Nee, V. (1997). Rethinking assimilation theory for a new era of immigration. International migration review, 31 (4), 826-874.

- Aliaga-Isla, R., \& Rialp, A. (2013). Systematic review of immigrant entrepreneurship literature: previous findings and ways forward. Entrepreneurship\& Regional Development, 25 (910), 819-844.

- Åslund, O., Edin, P. A., \& Fredriksson, P. (2001). Ethnic Enclaves and the Economic Success of Immigrants-Evidence from a Natural Experiment (No. 2729). CEPR Discussion Papers.
- Assis, G. D. O., \& Sasaki, E. M. (2001). Novos migrantes do e para o Brasil: um balanço da produção bibliográfica. Migrações internacionaiscontribuições para políticas. Brasilia: CNPD, 615639.

- Atkinson, R. (2006). Padding the bunker: strategies of middle-class disaffiliation and colonisation in the city. Urban Studies, 43 (4), 819-832.

- Barrett, G. A., Jones, T. P., \& McEvoy, D. (1996). Ethnic minority business: Theoretical discourse in Britain and North America. Urban studies, 33 (4-5), 783-809.

- Basu, A. (1998). An exploration of entrepreneurial activity among Asian small businesses in Britain. Small business economics, 10 (4), 313-326.

- Becker, G. S. (1964). Human capital theory. Columbia, New York.

- Bourdieu, P. (1986). The Forms of Capital. In handbook of theory and research for the sociology of education. Edited by: Richardson J.

- Carvalho e Silva, A.de; and C. Yen-Tsang. (2015). Tem Comida Chinesa no Prato dos Brasileiros: Como Empreendem os Imigrantes Chineses no Brasil? In: XXXIX Encontro da ANPAD - EnANPAD, 2015, Belo Horizonte. Anais do XXXIX Encontro da ANPAD - EnANPAD. Belo Horizonte.

- Chaganti, R., \& Greene, P. G. (2002). Who are ethnic entrepreneurs? A study of entrepreneurs, ethnic involvement and business characteristics. Journal of Small Business Management, 40 (2), 126-143.

- Clark, K., \& Drinkwater, S. (2000). Pushed out or pulled in? Self-employment among ethnic minorities in England and Wales. Labour Economics, 7 (5), 603-628.

- Collins, J. (2003). Cultural diversity and entrepreneurship: Policy responses to immigrant entrepreneurs in Australia. Entrepreneurship\& Regional Development, 15 (2), 137-149.

- Dobrev, S. D., \& Barnett, W. P. (2005). Organizational roles and transition to entrepreneurship. Academy of Management Journal, 48 (3), 433-449.

- Ellis, M., Wright, R., \& Parks, V. (2004). Work together, live apart? Geographies of racial and ethnic segregation at home and at work. Annals of the Association of American Geographers, 94 (3), 620-637.

- Evans, D. S., \& Leighton, L. S. (1989). Some empirical aspects of entrepreneurship. The American Economic Review, 79 (3), 519-535. 
- Fairlie, R. W., \& Meyer, B. D. (1996). Ethnic and racial self-employment differences and possible explanations. Journal of human resources, 31 (4), 757-793.

- Global Entrepreneurship Monitor [GEM] (2016). GEM REPORT 2015.

- Gordon, M. M. (1964). Assimilation in American life: The role of race, religion and national origins. Oxford University Press.

- Halter, M. (2007). Cultura econômica do empreendimento étnico: caminhos da imigração ao empreendedorismo. Revista de Administração de Empresas, 47 (1), 116-123.

- Iceland, J. (2004). Beyond black and white: metropolitan residential segregation in multiethnic America. Social Science Research, 33 (2), 248-271.

- Jensen, L., \& Portes, A. (1992). The enclave and the entrants: Patterns of ethnic enterprise in Miami before and after Mariel. American SociologicalReview, 57 (3), 411-414.

- Johnston, R., Forrest, J., \&Poulsen, M. (2002). Are there ethnic enclaves/ghettos in English cities? UrbanStudies, 39 (4), 591-618.

- Johnston, R., Poulsen, M., \& Forrest, J. (2007). The geography of ethnic residential segregation: a comparative study of five countries. Annals of the Association of American Geographers, 97 (4), 713738.

- Jones, M. V., Coviello, N., \& Tang, Y. K. (2011). International entrepreneurship research (19892009): a domain ontology and thematic analysis. Journal of business venturing, 26 (6), 632-659.

- Kloosterman, R. C. (2003). Creating opportunities. Policies aimed at increasing openings for immigrant entrepreneurs in the Netherlands. Entrepreneurship\& Regional Development, 15 (2), 167-181.

- Kontos, M. (2003). Self-employment policies and migrants' entrepreneurship in Germany. Entrepreneurship \& Regional Development, 15 (2), 119-135.

- Levitt, P. (1998). Social remittances: Migration driven local-level forms of cultural diffusion. International migration review, 32 (4), 926-948.

- Light, I. H. (1972). Ethnic enterprise in America: Business and welfare among Chinese, Japanese, and Blacks. University of California Press.
- Light, I. H. (1998). Immigrant Entrepreneurs in America. In: JACOBSON, D. (ed.) The Immigrant Reader-America in a Multidisciplinary Perspective. Blackwell Publishers.

- Light, I., \& Bonacich, E. (1988). Immigrant Entrepreneurs. Berkeley. Cal.: University of California Press.

- Light, I., Sabagh, G., Bozorgmehr, M., \& DerMarirosian, C. (1994). Beyond the ethnic enclave economy. Social Probems, 41 (1), 65-80.

- Logan, J. R., Alba, R. D., \& McNulty, T. L. (1994). Ethnic economies in metropolitan regions: Miami and beyond. Social Forces, 72 (3), 691-724.

- Logan, J. R., Alba, R. D., \& Stults, B. J. (2003). Enclaves and Entrepreneurs: Assessing the Payoff for Immigrants and Minorities1. International Migration Review, 37 (2), 344-388.

- Logan, J. R., Zhang, W., \& Alba, R. D. (2002). Immigrant enclaves and ethnic communities in New York and Los Angeles. American sociological review, 67 (2), 299-322.

- Loscocco, K. A., \& Robinson, J. (1991). Barriers to women's small-business success in the United States. Gender\&Society, 5 (4), 511-532.

- Ma, Z., Zhao, S., Wang, T., \& Lee, Y. (2013). An overview of contemporary ethnic entrepreneurship studies: themes and relationships. International Journal of Entrepreneurial Behavior \& Research, 19 (1), 3252.

- Margolis, M. (2003). Na virada do milênio: a emigração brasileira para os Estados Unidos. Fronteiras cruzadas: etnicidade, gênero e redes sociais. São Paulo: Paz e Terra, 51-72.

- Martes, A. C. B., \& Rodriguez, C. L. (2004). Afiliação religiosa e empreendedorismo étnico: o caso dos brasileiros nos Estados Unidos. Revista de Administração Contemporânea, 8 (3), 117-140.

- Masurel, E., \& Nijkamp, P. (2004). Differences between first-generation and second-generation ethnic start-ups: implications for a new support policy. Environment and Planning C: Government and Policy, 22 (5), 721-737.

- Nakahata, F. T., \& Teixeira, R. M. (2014). Sucesso e fracasso na criação de negócios pelos dekasseguis: estudo de casos múltiplos no noroeste do Paraná. Revista de Gestão, 21 (1), 139-159.

- Ndofor, H. A., \&Priem, R. L. (2011). Immigrant entrepreneurs, the ethnic enclave strategy, and venture performance. Journal of Management, 37 (3), 790-818. 
- Nee, V., \& Sanders, J. (2001). Understanding the diversity of immigrant incorporation: a forms-ofcapital model. Ethnic and racial studies, 24 (3), 386-411.

- Nee, V., Sanders, J. M., \&Sernau, S. (1994). Job transitions in an immigrant metropolis: ethnic boundaries and the mixed economy. American sociological review, 59 (6), 849-872.

- Nijkamp, P. (2003). Entrepreneurship in a modern network economy. Regional Studies, 37 (4), 395405.

- Oliveira, J. F. (2007). Empreendedorismo Sem Fronteira: desafios e conquistas dos imigrantes chineses no Brasil. In: XXXI Encontro da ANPAD EnANPAD, 2007, Rio de Janeiro. Anais do XXXI Encontro da ANPAD - EnANPAD. Rio de Janeiro.

- Oliveira, M. D. F. S., \& Iglesias, J. C. G. (2012). El inmigrante transnacional y la conducta emprendedora. Revista Capital CientíficoEletrônica (RCCe), 10 (2), 94-109.

- Petticrew, M. (2006). Systematic Reviews in the Social Sciences: A Critical Guide. Malden, MA:Blackwell.

- Portes, A, \& Sensenbrenner, J. (1993). Embeddedness and Immigration: Notes on the Social Determinants of Economic. American Journal of Sociology, 98 (6), 1320-1350.

- Portes, A. (1987). The social origins of the Cuban enclave economy of Miami. Sociological perspectives, 30 (4), 340-372.

- Portes, A. (2010). Migration and social change: Some conceptual reflections. Journal of ethnic and migration studies, 36 (10), 1537-1563.

- Portes, A., \& Jensen, L. (1989). The enclave and the entrants: Patterns of ethnic enterprise in Miami before and after Mariel. American Sociological Review, 54 (6), 929-949.

- Portes, A., \&Schauffler, R. (1994). Language and the second generation: Bilingualism yesterday and today. International migration review, 640-661.

- Portes, A., \& Zhou, M. (1996). Self-employment and the earnings of immigrants. American Sociological Review, 61 (2), 219-230.

- Portes, A., \& Zhou, M. (1992). Gaining the upper hand: Economic mobility among immigrant and domestic minorities. Ethnicand Racial Studies, 15, 491-522.

- Portes, A., Guarnizo, L. E., \& Haller, W. J. (2002). Transnational entrepreneurs: An alternative form of immigrant economic adaptation. American sociological review, 67 (2), 278-298.

- $\quad$ Putnam, R. D., Leonardi, R., \&Nanetti, R. Y. (1994). Making democracy work: Civic traditions in modern Italy. Princeton university press.

- Raijman, R. (2001). Determinants of entrepreneurial intentions: Mexican immigrants in Chicago. The Journal of Socio-Economics, 30 (5), 393-411.

- Sanders, J. M. (2002). Ethnic boundaries and identity in plural societies. Annual Review of Sociology, 28, 327-357.

- Sanders, J. M., \& Nee, V. (1987). Limits of ethnic solidarity in the enclave economy. American Sociological Review, 52 (6), 745-773.

- Sanders, J. M., \& Nee, V. (1996). Immigrant selfemployment: The family as social capital and the value of human capital. American sociological review, 61 (2), 231-249.

- Sasse, G., \& Thielemann, E. (2005). A research agenda for the study of migrants and minorities in Europe. JCMS: Journal of Common Market Studies, 43 (4), 655-671.

- Thorpe, R., Holt, R., Macpherson, A., \& Pittaway, L. (2005). Using knowledge within small and medium-sized firms: A systematic review of the evidence. International Journal of Management Reviews, 7 (4), 257-281.

- Truzzi, O., M. S., \& Sacomano Neto, M. (2007). Economia e empreendedorismo étnico: balanço histórico da experiência paulista. Revista de Administração de Empresas, 47 (2), 1-12.

- Van der Sluis, J., Van Praag, M., \& Vijverberg, W. (2008). Education and entrepreneurship selection and performance: A review of the empirical literature. Journal of economic surveys, 22 (5), 795841.

- Vinogradov, E., \&Kolvereid, L. (2007). Cultural background, human capital and self-employment rates among immigrants in Norway. Entrepreneurship and Regional Development, 19 (4), 359-376.

- Vinogradov, E., \&Kolvereid, L. (2010). Home country national intelligence and self-employment rates among immigrants in Norway. Intelligence, 38 (1), 151-159.

- Vitorio, B. da S. (2007). Imigração brasileira em Portugal: identidade e perspectivas. Santos: Editora Universitária Leopoldianum. 
- Waldinger, R. (1993). The ethnic enclave debate revisited. International journal of urban and regional research, 17 (3), 444-452.

- Waldinger, R. (1995). The 'other side' of embedded ness: A case-study of the interplay of economy and ethnicity. Ethnic and racial studies, 18 (3), 555-580.

- Walks, R., \& Bourne, L. S. (2006). Ghettos in Canada's cities? Racial segregation, ethnic enclaves and poverty concentration in Canadian urban areas. The Canadian Geographer/Le Géographecanadien, 50 (3), 273-297.

- Waters, M. C., \& Eschbach, K. (1995). Immigration and ethnic and racial inequality in the United States. Annual Review of Sociology, 21, 419-446.

- Weinberg, M. F. (2004). 'Isha Mehagueret': judia imigrante empreendedora em São Paulo (1945-
1956). Sæculum-Revista de História, 11, 137-144.

- Wennekers, A., A. Thurik, A. van Stel, and N. Noorderhaven. (2003). Uncertainty avoidance and the rate of business ownership across 21 oecd countries, 1976-2004. Journal of Evolutionary Economics, 17 (2), 133-160.

- Wilson, K. L., \& Martin, W. A. (1982). Ethnic enclaves: A comparison of the Cuban and Black economies in Miami. American Journal of Sociology, 88 (1), 135-160.

- Zhou, M. (2004). The Role of the Enclave Economy in Immigrant Adaptation and Community Building: The case of New York's Chinatown. In: Immigrant and Minority Entrepreneurship. The Continuous Rebirth of American Communities. John Sibley Butler \& Geroge Kozmetsky. PRAGER: London.

\section{Sobre os autores}

- Eduardo Picanço Cruz é Doutor em Engenharia Química pela Universidade Federal do Rio de Janeiro (2007). Atualmente é professor Associado I do Departamento de Empreendedorismo e Gestão - STE da Universidade Federal Fluminense, UFF/RJ, Niterói/RJ, Brasil.E-mail: epicanco@id.uff.br

- Roberto Pessoa de Queiroz Falcão é Doutorando em Administração na IAG/PUC/RJ. Atualmente é professor substituto do Departamento de Empreendedorismo e Gestão - UFF/RJ e professor do MBA Empreendimentos Turísticos - UFF e do Laboratório de Tecnologia, Gestão de Negócios e Meio Ambiente-LATEC marketing. E-mail: robertopqfalcao@gmail.com 


\title{
A bibliometric review of Immigrant and Ethnic Entrepreneurship
}

\author{
Eduardo Picanço Cruz $^{\mathrm{A}}$ and Roberto Pessoa de Queiroz Falcão ${ }^{\mathrm{AB}}$
}

${ }^{A}$ Universidade Federal Fluminense, UFF/RJ, Rio de Janeiro/RJ, Brasil

${ }^{B}$ Pontifícia Universidade Católica do Rio de Janeiro, PUC/RJ, Rio de Janeiro/RJ, Brasil

ARTICLE DETAILS
Article history:
Received 26 July 2016
Accepted 07 December 2016
Available online in 30 December 2016
Double Blind Review System
Scientific Editor
Ilan Avrichir

Keywords:

Immigration

Immigrant Entrepreneurship

Ethnic Entrepreneurship

Ethnic Enclave

\begin{abstract}
Debate about the immigration of thousands of refugees to Europe and their assimilation by society and the local economy is a popular theme today. Furthermore, international entrepreneurship of ethnic enclaves has been studied as a form of social mobility and integration of these groups. Several immigrant communities of various ethnic groups have been studied, however, the Brazilian immigrant has been little studied in relation to his/her profile, culture, and entrepreneurial behavior. Bibliometric research conducted on immigrant and ethnic entrepreneurship points to a change in its original focus on "enclave economies," "ethnic business," and "social embeddedness" to studies related to "immigrant entrepreneurs," "immigrant business networks," and "transnational entrepreneurs." This article aims to present the results of a bibliometric study, contemplating seminal works, the main international theories on immigrant entrepreneurship, and ethnic enclaves. Moreover, gaps in Brazilian and international literature are also identified in order to systematically expand this field of research. The authors present an analysis of concepts, theories, and the most cited articles in this study field, as well as pointing to possible future research directions.
\end{abstract}

(C) 2016 Internext | ESPM. All rights reserved!

Para citar este artigo:

Cruz, E. P. and Falcão, R. P. Q. (2016) Revisão bibliométrica no tema Empreendedorismo Imigrante e Étnico. Internext - Revista Eletrônica de Negócios Internacionais, 11 (3), 78-94. DOI: 10.18568/19804865.11378-94

Para acessar este artigo: $h t t p: / / d x . d o i . o r g / 10.18568 / 1980-4865.11378-94$ 